\title{
COMPOSITE POLYMER ELECTROLYTES USING FUMED SICICA FILLERS: SYNTHESIS, RHEOLOGY AND ELECTROCHEMISTRY
}

\author{
Saad A. Khan and Peter S. Fedkiw \\ Department of Chemical Engineerring \\ North Carolina State University, Raleigh, NC 27695-7905 \\ Ph: 919-515-4519; email:khan@eos.ncsu.edu \\ Gregory L. Baker \\ Department of Chemistry \\ Michigan State University, East Lansing, MI 48824-1322
}

\section{A Final Year Report submitted to the}

\section{U.S. Department of Energy}

94-ER-14495

Our goal for the project initiated in 1994 was to show that composite polymer electrolytes can be developed with the following desirable properties: a) processability, b) mechanical strength, c) ionic conductivity that rivals gel electrolytes, and d) electrochemical stability. Several composite electrolyte systems were developed using different oligomers, salts and fumed silica (Table 1), although all not possible permutations were examined. Our principal findings reveal that fumed-silica composites (bearing cross-linked or uncross-linked surface groups) exhibit:

- room temperature ionic conductivities exceeding $1 \times 10^{-3} \mathrm{~S} / \mathrm{cm}$

- high mechanical strength with an elastic modulus similar to elastomers (e.g., $\sim 10^{5} \mathrm{~Pa}$ )

- shear thinning viscosity leading to easy processability

- improved electrochemical stability with lithium

In addition, our preliminary full-cell cycling tests show that the composite electrolyte functions well when using $\mathrm{LiCoO}_{2}$ or $\mathrm{LiMn}_{2} \mathrm{O}_{4}$ as the cathode.

These results are extremely encouraging, and selected aspects of these are discussed below in more detail. 


\section{DISCLAIMER}

This report was prepared as an account of work sponsored by an agency of the United States Government. Neither the United States Government nor any agency thereof, nor any of their employees, make any warranty, express or implied, or assumes any legal liability or responsibility for the accuracy, completeness, or usefuiness of any information, apparatus, product, or process disclosed, or represents that its use would not infringe privately owned rights. Reference herein to any specific commercial product, process, or service by trade name, trademark, manufacturer, or otherwise does not necessarily constitute or imply its endorsement, recommendation, or favoring by the United States Government or any agency thereof. The views and opinions of authors expressed herein do not necessarily state or reflect those of the United States Government or any agency thereof. 


\section{DISCLAIMER}

Portions of this document may be illegible in electronic image products. Images are produced from the best available original document. 
Table 1: Components of Various Composite Polymer Electrolytes

\begin{tabular}{|c|c|c|}
\hline Oligomer & Salt & Fumed Silica \\
\hline $\begin{array}{c}\text { PEG (MW 300) } \\
\text { polyethylene glycol }\end{array}$ & $\begin{array}{l}\mathrm{Li}\left(\mathrm{CF}_{3} \mathrm{SO}_{2}\right)_{2} \mathrm{~N} ; \\
\text { (lithium imide) }\end{array}$ & R805 (50\% octyl coverage)* \\
\hline $\begin{array}{l}\text { PEG-M (MW 350) } \\
\text { methyl capped PEG }\end{array}$ & $\begin{array}{l}\mathrm{LiCF}_{3} \mathrm{SO}_{3} \text { ( (lithium } \\
\text { triflate) }\end{array}$ & TCSOl (various degrees of octyl group coverage) ${ }^{+}$ \\
\hline $\begin{array}{l}\text { PEG-DM (MW 250) } \\
\text { dimethyl capped PEG }\end{array}$ & $\begin{array}{l}\mathrm{LiClO}_{4} ; \text { (lithium } \\
\text { perchlorate) }\end{array}$ & A200 (native silanol)* \\
\hline \multirow[t]{4}{*}{ PEG-DM (MW 500) } & & R711 (methacrylate modified at unknown coverage)* \\
\hline & & R974 (50\% methyl coverage)* \\
\hline & & $\begin{array}{c}\text { TGA1A1 (PEO modified silicas, various chain } \\
\text { lengths) })^{+}\end{array}$ \\
\hline & & TOM (octyl and methacrylate modified) ${ }^{+}$ \\
\hline
\end{tabular}

*Available from Degussa Corporation; ${ }^{+}$Synthesized at MSU

Synthesis

The goal of the synthesis research was to devise routes to PEG/fumed silica/lithium salt composites that can be processed and then photochemically cross-linked to form mechanically stable electrolytes. An essential feature of the system is that the ionic conductivity and the mechanical properties must be de-coupled from each other, i.e., cross-linking of the fumed silica matrix must not cause a significant deterioration of the conductivity of the composite. As shown in Figure 2, we prepared a range of surface-modified fumed silicas and investigated their ability to form mechanically stable composite electrolytes. The groups used to modify the surface properties of the silica ranged from simple linear alkyls that render the silica hydrophobic, to polyethers that promote compatibility with the electrolyte. From these materials we developed a cross-linkable system that satisfies the criteria of processibility and high conductivity.

The key material needed for the cross-linking reaction are silicas that bear surfaceattached monomers. As show schematically in Figure 3a, we prepared fumed silicas with a combination of surface groups, for example, an octyl chain with different coverages of tethered methacrylates. The length of the tether was varied, and we found that both $C_{3}$ and $C_{8}$ tethers gave useful composites. The functionalized silicas were combined with PEG-DM, AIBN or benzophenone (free radical initiators), $\mathrm{LiClO}_{4}$ or $\mathrm{Li}$ imide, and either methyl, butyl, or octyl, methacrylate to form stable clear gels. Upon irradiation with UV light, polymerization of both the tethered methacrylate and the added methacrylate took place, yielding a cross-linked rubbery composite material. Ionic conductivity measurements before and after cross-linking showed only a slight decrease (see Figure 9 later), thereby offering strong experimental evidence that the mechanical properties conferred by the silica matrix are de-coupled from the ionic conductivity of the PEG-DM matrix. 


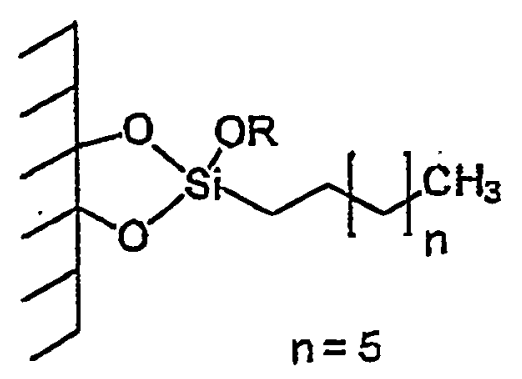<smiles>[R][Si]1(CCCCCC)OC(C)(C(C)CC)C(C)(C(C)CC)O1</smiles><smiles>[R][Si]1(CCC(C)(C)OCCOC)OC(C)(C(C)CC)C(C)(C(C)CC)O1</smiles>

polyether side chain, inproves compatibility with PEG-DM matrix<smiles>[R][Si]1(CCCCOC2CCCCO2)OC(C)(C(C)CC)C(C)(C(C)CC)O1</smiles><smiles>[R][Si]1(CCCCO)OC(C)(C(C)CC)C(C)(C(C)CC)O1</smiles>

terminal alcohol to promote hydrogen bonding

Figure 2. Scope of silica bound functional groups synthesized to date. The lengths of the tethered chains, i.e., $n$, can be varied as desired. 


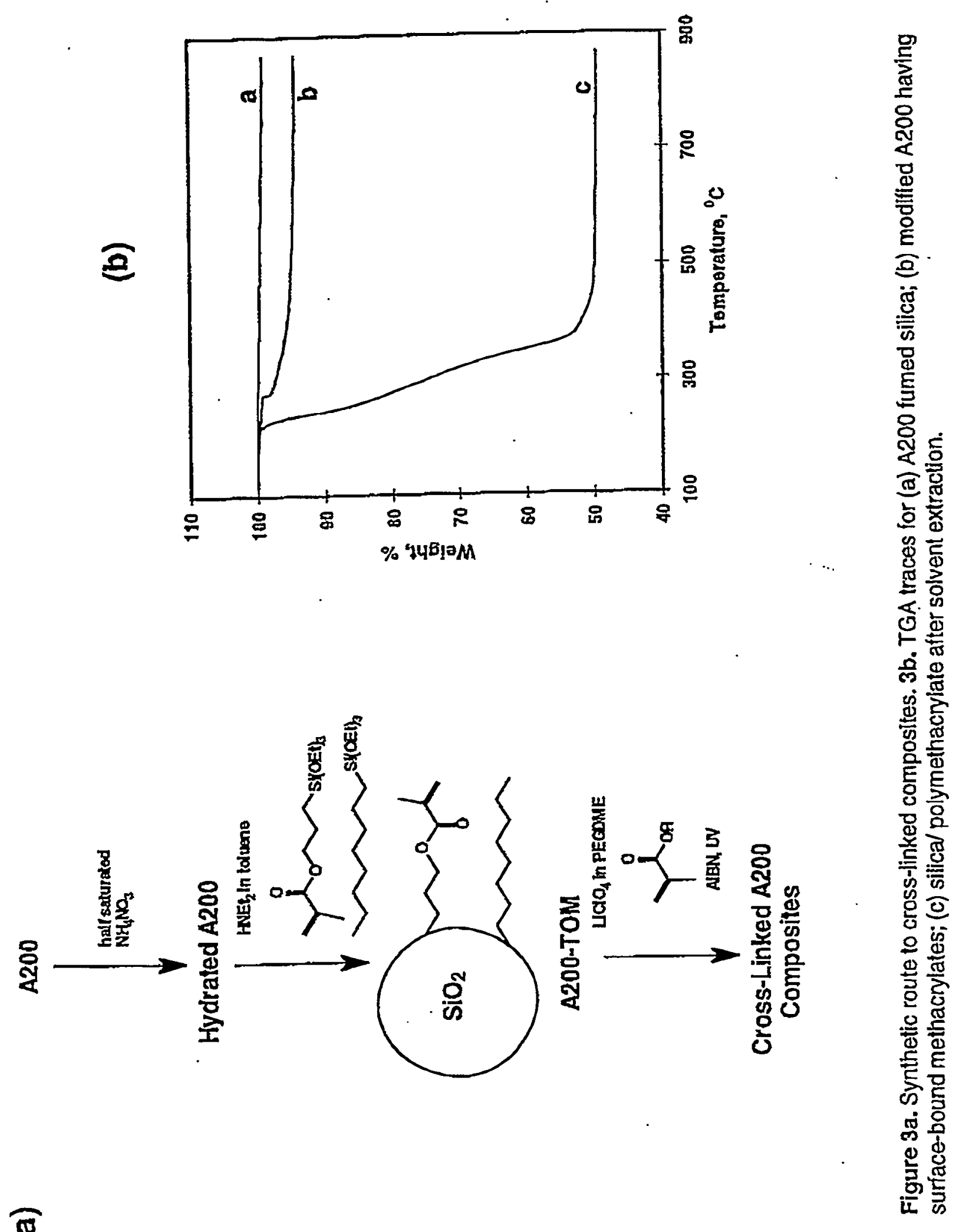

5 
The significance of this work is that highly processable composite electrolytes can now be converted by standard polymer curing processes into dimensionaly stable electrolytes without significant losses in ionic conductivity.

Key to optimizing the crossulinking reaction is an understanding of the fate of the added methacrylate monomer, which is initially soluble in the PEG-DM. Two limiting models for the cross-linking reaction are: (1) that a homogeneous dispersion of polymer chains is formed in the PEG-DM to give an intexpenetrating network, and (2) that polymerization is localized near the added fumed silica to give a polymethacrylate/fumed silica phase. To test these possibilities, cross-linked composites were extracted with solvent to remove PEG-DM, salts, and unreacted monomer. The residue, fumed silica plus any polymethacrylate chains that had been chemically linked to the silica, was analyzed by Thermal Gravimetric Analysis (Figure 3b). The expected weight loss resulting from decomposition of the organic fragments initially bound to the fumed - silica is $4 \%$. If all of the added methacrylate monomer was chemically linked (copolymerized) to the silica, then the expected weight loss would be $56 \%$. As seen in the figure, a $52 \%$ loss was found, thus providing a clear indication that nearly all of the monomer is chemically bound to the silica.

A model for the cross-linking reaction consistent with the data is that as the monomer polymerizes, the polymer phase separates from the PEG-DM and concentrates in the fumedsilica phase. Model polymerizations of methacrylates in PEG-DM support this picture. As polymerization proceeds, the solutions become cloudy and the polymethacrylate separates to form distinct phases. The effect is most pronounced for the least polar monomer, octyl methacrylate, for which the driving force for phase separation would be expected to be the greatest. Qualitatively, the same observations were made for composite electrolytes during cross-linking.

\section{Electrochemical Studies}

We present selected results in order to conserve space, but the full collection of data and accompanying discussion, along with experimental details, are available elsewhere [32]. The most extensive studies to date have used the commercially available, octyl-modified fumed silica R805. In terms of network formation, these silicas behave similarly to those used in forming cross-linked composites. Because only PEG-DM. did not show visible indications of reaction with a freshly polished lithium foil, the majority of the studies (other than conductivity measurements) routinely employed it as the solvent. The salt content of $1: 20(\mathrm{Li}: 0)$ yielded the maximum room-temperature conductivity for both triflate and imide salts in this solvent.

Figure 4 shows the effects of temperature and weight percentage of R805 on conductivity using the imide salt. As expected, non-Arrhenius behavior is observed [6,33]. The roomtemperature conductivity in the absence of fumed silica is $1.5 \times 10^{-3} \mathrm{~S} / \mathrm{cm}$ and drops only $5 \%$ at 10 wt $\%$ solids, and even at $20 \mathrm{wt} \%$, the conductivity at room temperature remains above the necessary practical value quoted by Fauteux et al. [7] of $10^{-3} \mathrm{~S} / \mathrm{cm}$.

Figure 5 shows that the potential window is approximately $5.5 \mathrm{~V}$ for the composite electrolyte, which is sufficiently large for high-potential, intercalation cathodes such as $\mathrm{LiNiO}_{2}$, $\mathrm{LiCOO}_{2}$, and $\mathrm{LiMn}_{2} \mathrm{O}_{4}$.

Figure 6 shows the chemical stability of lithium with the composite electrolyte, as defined by the diameter of the semicircle subtended on the real axis of the Nyquist plot of the 


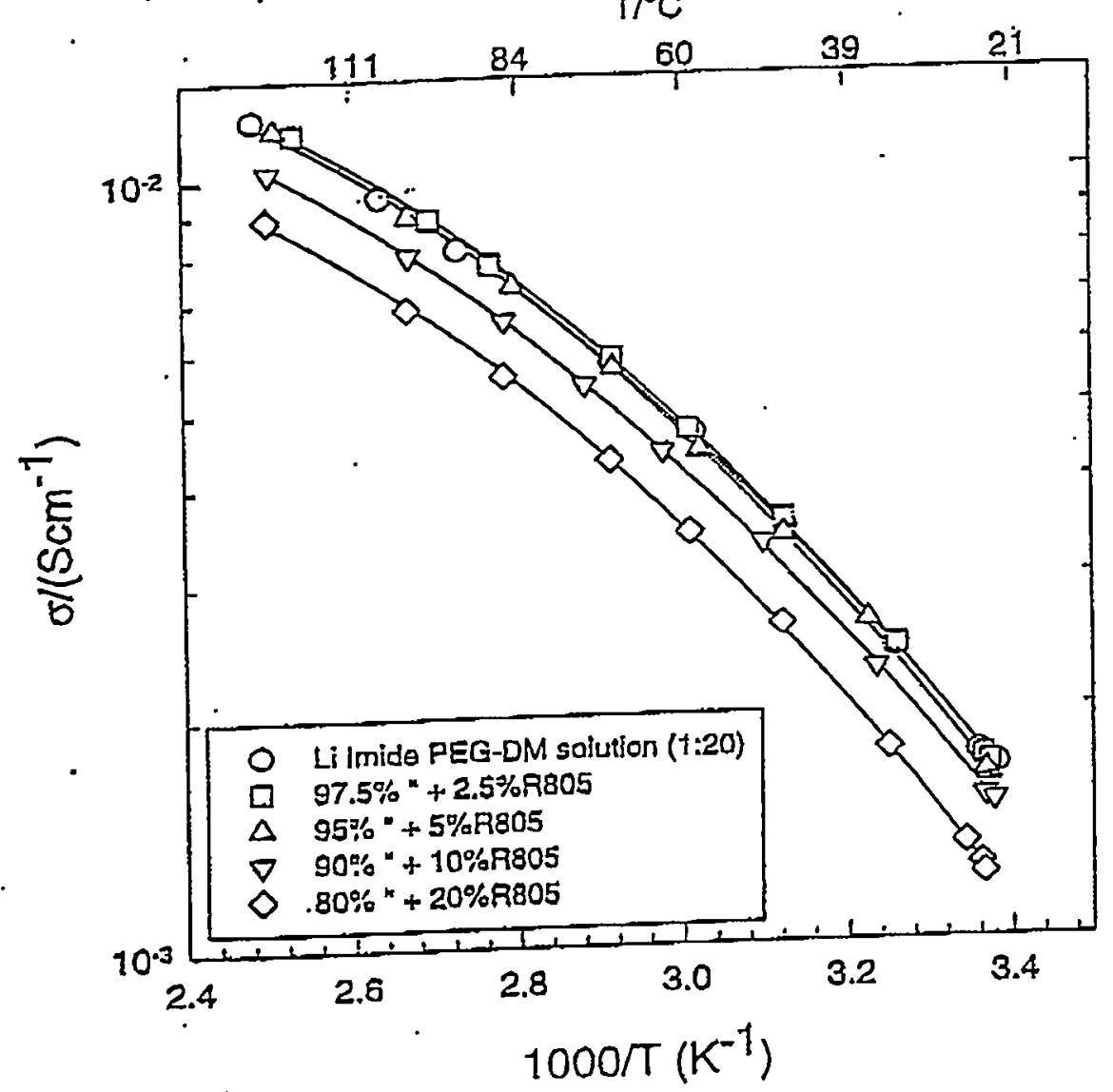

Figure 4. Conductivity of $\mathrm{Li}$ imide+PEG-DM+R805 fumed silica composife electrolyte.

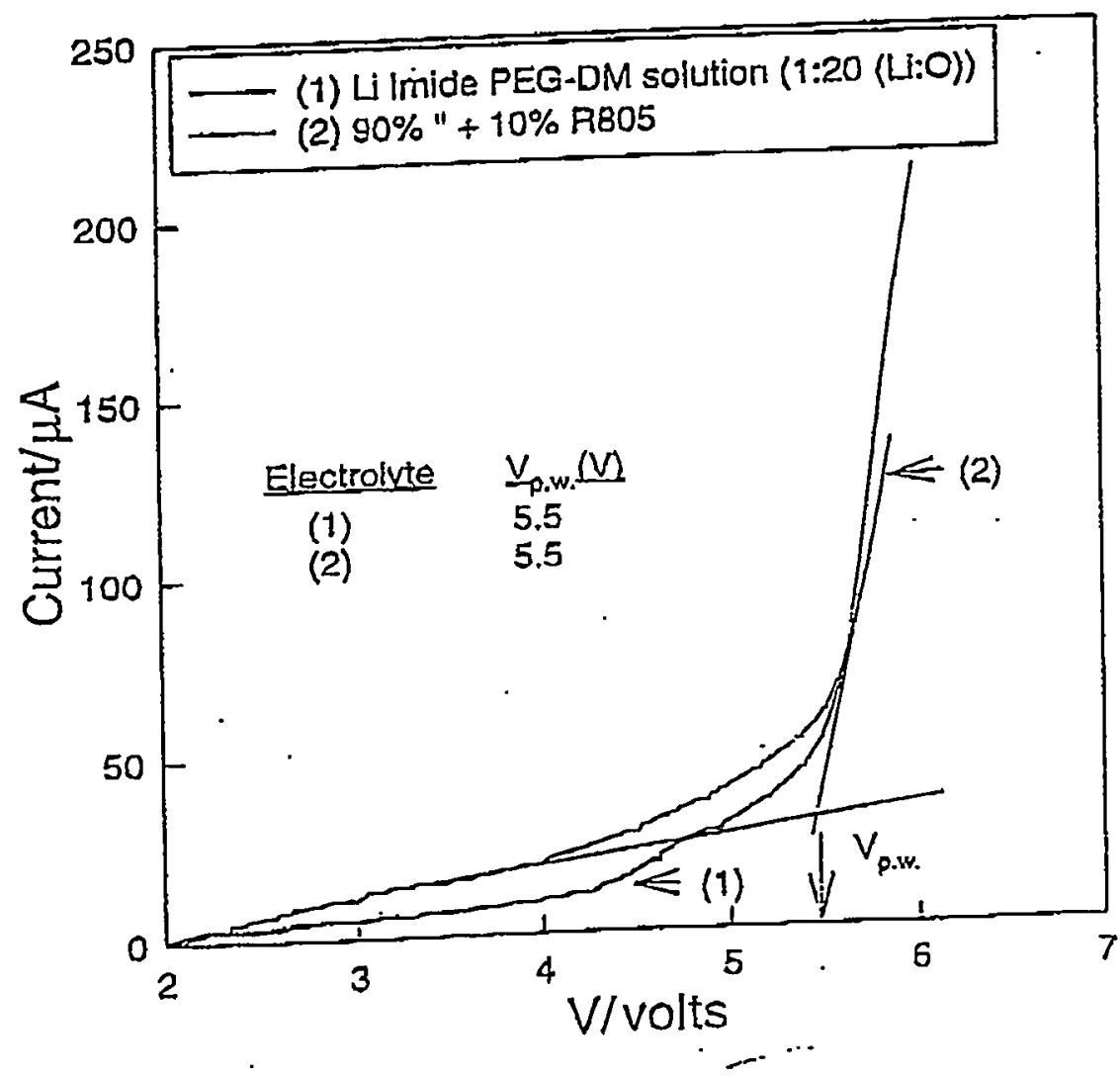

Figure 5. Ohmic-compensated linear sweep voltammogram for $\mathrm{Li}$ imide+PEG-DM, with and without R805 fumed silica. The potential window $V_{\text {p.w. }}$ was obtained as indicated on figure. Voltage is relative to lithium reference electrode, and electrode area is $1.5 \mathrm{~cm}^{2}$. 


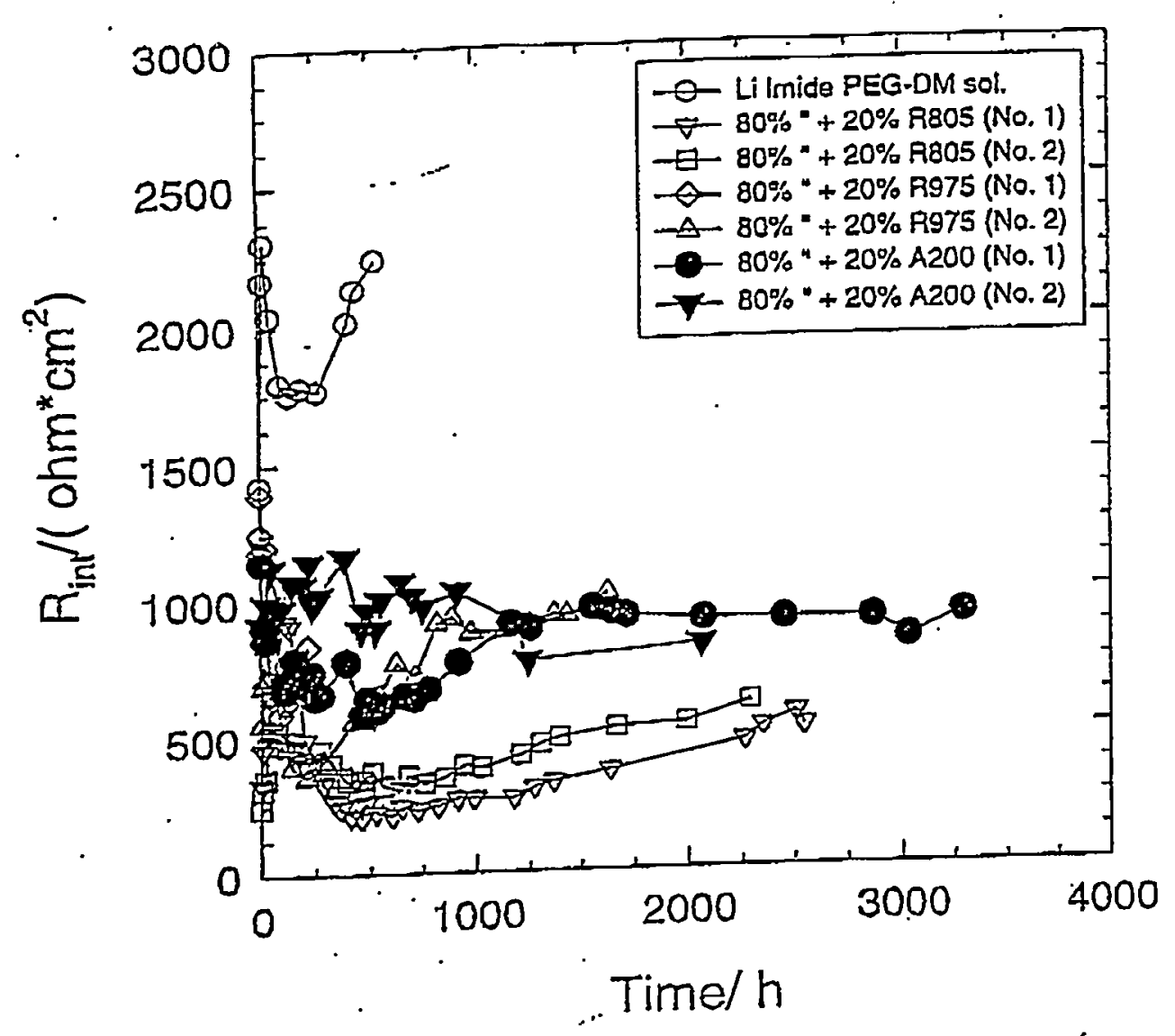

Figure 6. Time dependence of lithium-electrolyte interfacial impedance for $\mathrm{Li}$ imide + PEG-DM (Li:O of 1:20), in the presence and absence of various types of fumed silica.

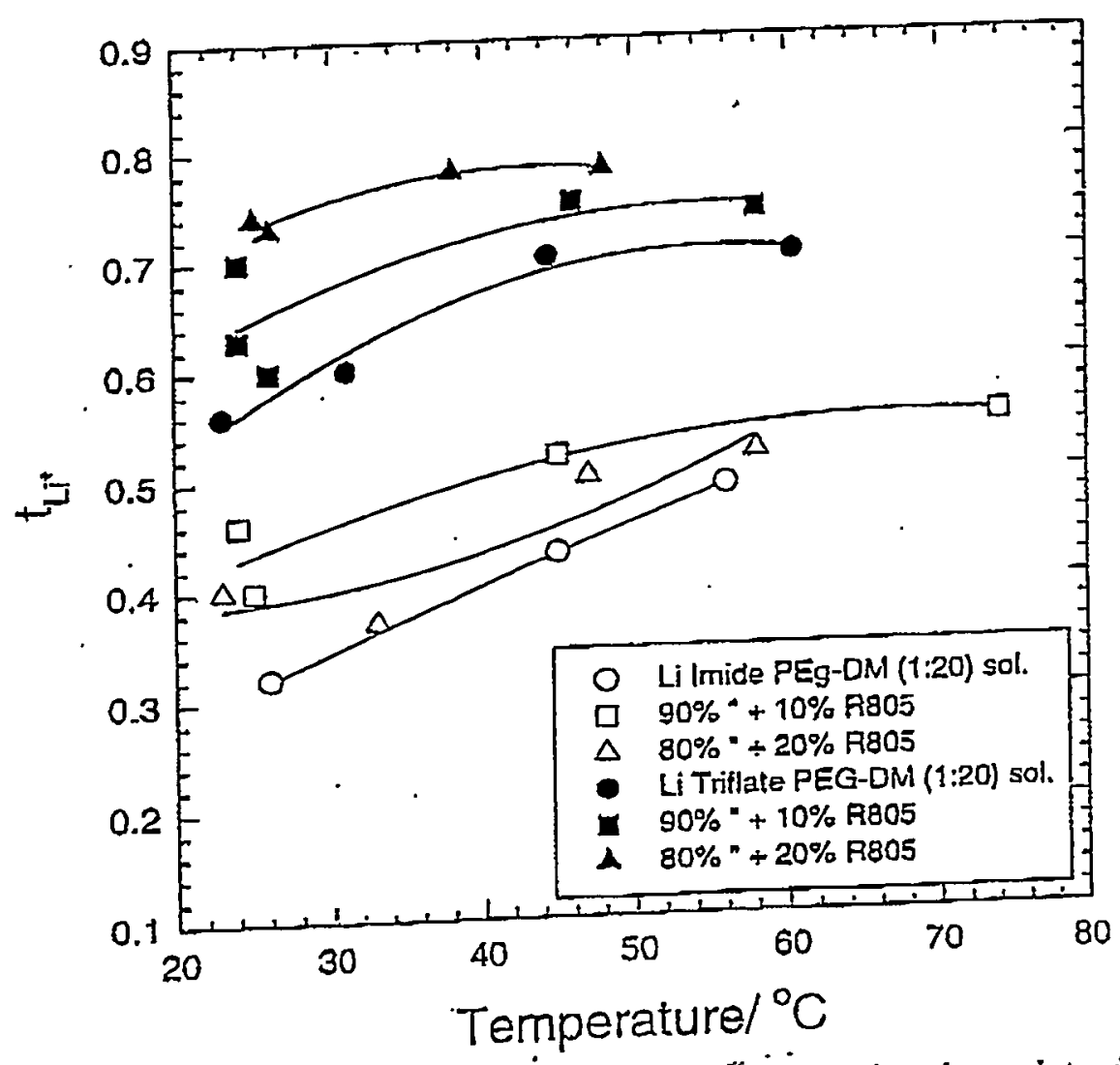

Figure 7. Lithium transference number for fumed-silică composite electrolyte determined according to the method of Bruce and Vincent (1987). 
impedance results [32]. The interface is unstable in the absence of fumed silica: the interfacial impedance continually increased (after an initial decrease). This result is congruent with the recent work of Aurbach and Granot [34] who, using a combination of IR spectroscopy, SEM visualization, and electrochemical response, reported that lithium is not stable in contact with triflate and imide salts, among others, dissolved in diglymes. However, an unexpected but reproducible result (replicate data sets are provided on the Figure) is that fumed silica stabilizes the interface, regardless of the functionalization (hydroxyl, methyl, or octyl) of the particle surface. Other researchers have reported similar stabilization phenomena for particulates dispersed in high-MW PEO in contact with lithium $[15,18]$. This stabilization may provide significant technological and safety advantages to these electrolytes.

Figure 7 shows the temperature dependence of $\mathrm{Li}^{+}$transference number for the composite electrolyte using the imide or triflate salt. These values were determined by the method of Bruce and Vincent [35]. Although this method has been criticized [36] and there is ambiguity in interpretation of the ordinate value, the relative trends and differences in the data are meaningful. Again, the fumed silica seems to have a beneficial effect: the transference number is greater in its presence, with all other things remaining equal.

Figure 8 illustrates full-cell cycling results for a lithium cell with a $\mathrm{LiMn}_{2} \mathrm{O}_{4}$ (8a) or $\mathrm{LiCoO}_{2}(8 \mathrm{~b})$ cathode. The composite electrolyte is seen to function well over the limited cycles performed so far. These cycling studies remain in progress but are strongly encouraging: There is no significant capacity fade, and the measured capacity of 100 and $105 \mathrm{mAh} / \mathrm{g}$ for $\mathrm{LiMn}_{2} \mathrm{O}_{4}$ and $\mathrm{LiCoO}_{2}$, respectively, in this not-yet optimized system are $83 \%$ and $77 \%$ of the respective maximum practical capacities [37].

Figure 9 illustrates that the conductivity of the TOM sample (octyl and methacrylate modified, Table 1) before and after thermal cross-linking is lowered, at most, by a factor of 2 , and the room-temperature value remains $>10^{-3} \mathrm{~S} / \mathrm{cm}$.

\section{Rheological Behovior}

Two critical criteria for useful composite electrolytes are that they be mechanically strong yet processable. We employed dynamic rheology [38] to probe the microstructure of these systems [29,30], and steady shear rheology [36] to determine the processability of fumed-silica composites [29,39]. In Figure 10, we show the elastic ( $G^{\prime}$ ) and viscous ( $\left.G^{\prime \prime}\right)$ moduli of composite polymer electrolytes composed of $5 \% \mathrm{R} 805$ fumed silica in a matrix formed by various lithium salts and PEG-DM. In all three samples we find $G^{\prime}$ to be significantly larger than $G$ ' with both moduli being frequency-independent. These features are characteristic of materials with three-dimensional network structures behaving as elastic gels [27,40,41], thereby indicating that the electrolyte system acts as an elastic solid. Moreover, we find the moduli are largely insensitive to the lithium salt type. This is advantageous for designing composite electrolytes in that one can use different salts to tailor the electrochemical properties without affecting the mechanical properties of the composite.

In Figure 11, we show the effect of R805 fumed-silica concentration on both room temperature conductivity and elastic modulus for a PEG-DM/ithium imide system. Addition of fumed silica leads to large increases in elastic modulus $G^{\prime}$. For example, addition of 20 wt. \% R805 leads to a $\mathrm{G}^{2} \sim 10^{5} \mathrm{~Pa}$ a value comparable to many rubbery polymeric materials. More importantly, the enhanced mechanical stability is accompanied by only a small loss in 
(a)

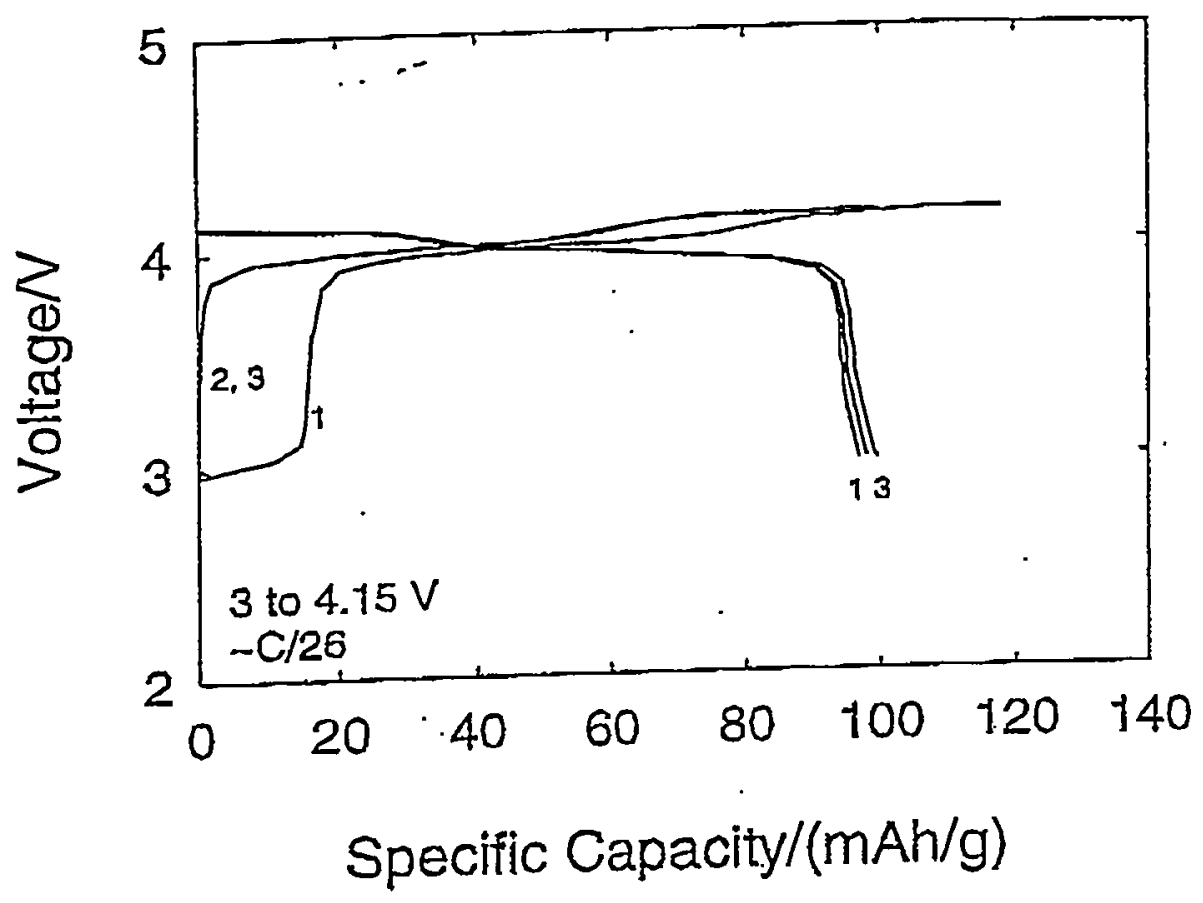

(b)

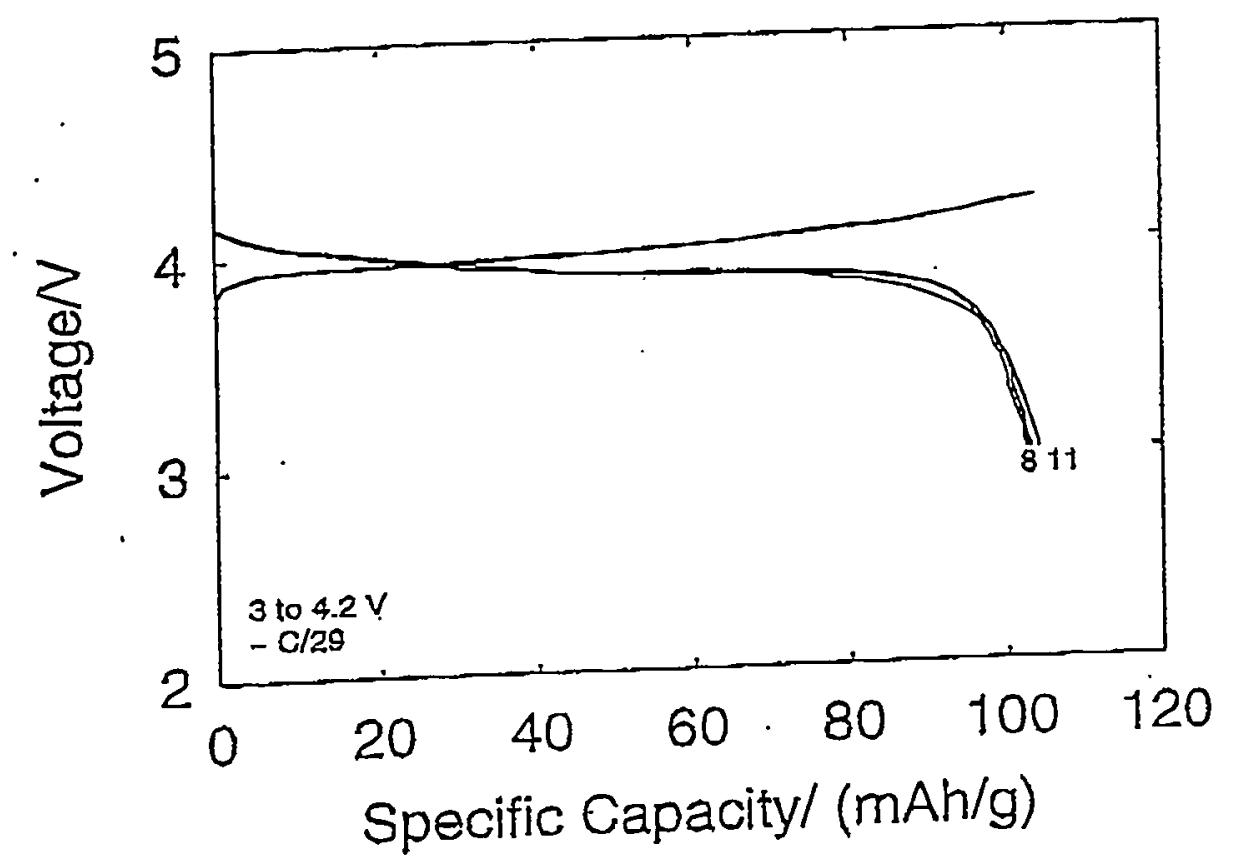

Figure 8. Constant current, full-cell cycling results using the composite electrolyte PEG$\mathrm{DM}+\mathrm{Li}$ Imide $+15 \% \mathrm{R} 805$ fumed silica ( $\mathrm{Li}: \mathrm{O}$ of $1: 20$ ). The cut-off voltages and chargedischarge rates are shown on the figure. The cell was a button cell of $1.6-\mathrm{cm}$ diameter

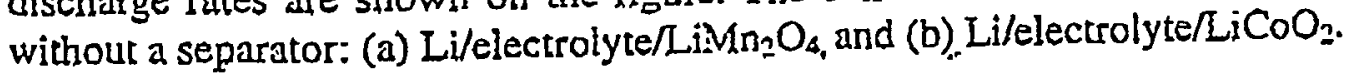




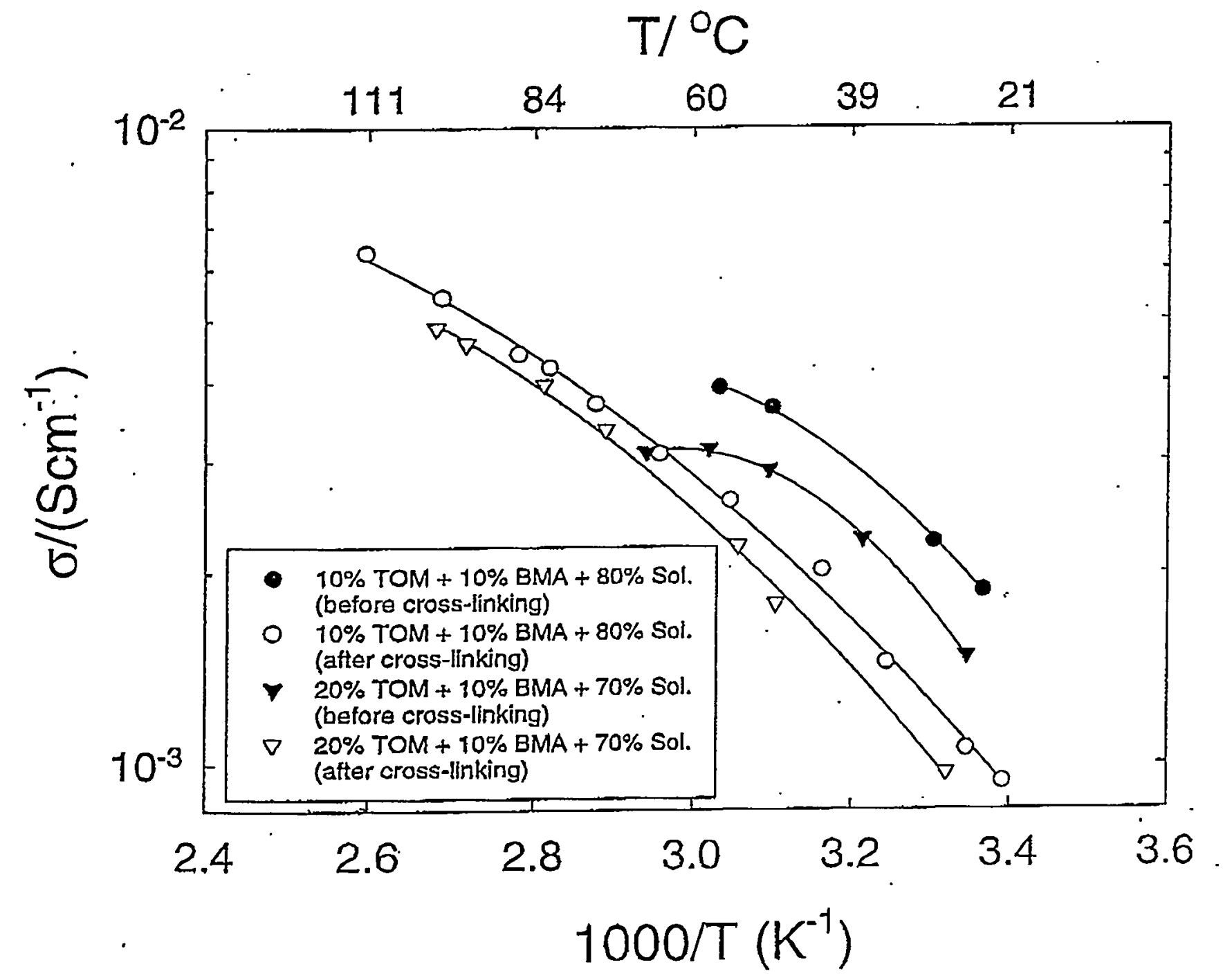

Figure 9. Conductivity of functionalized 4200 fumed silica (octyl + methacrylate) before and after thermally-induced crosslinking. Solution (Sol.) referenced in legend is $\mathrm{Li}$ Imide+PEG-DM (Li:O of 1:20). Butyl methacrylate (Bi)A) was added to the solution along with a free-radical initiator, and the anomalous curvature in the conductivity results at elevated temperatures is due to the occurrence of the crosslinking reaction during the measurement. Proportions are given in weight percentage. 


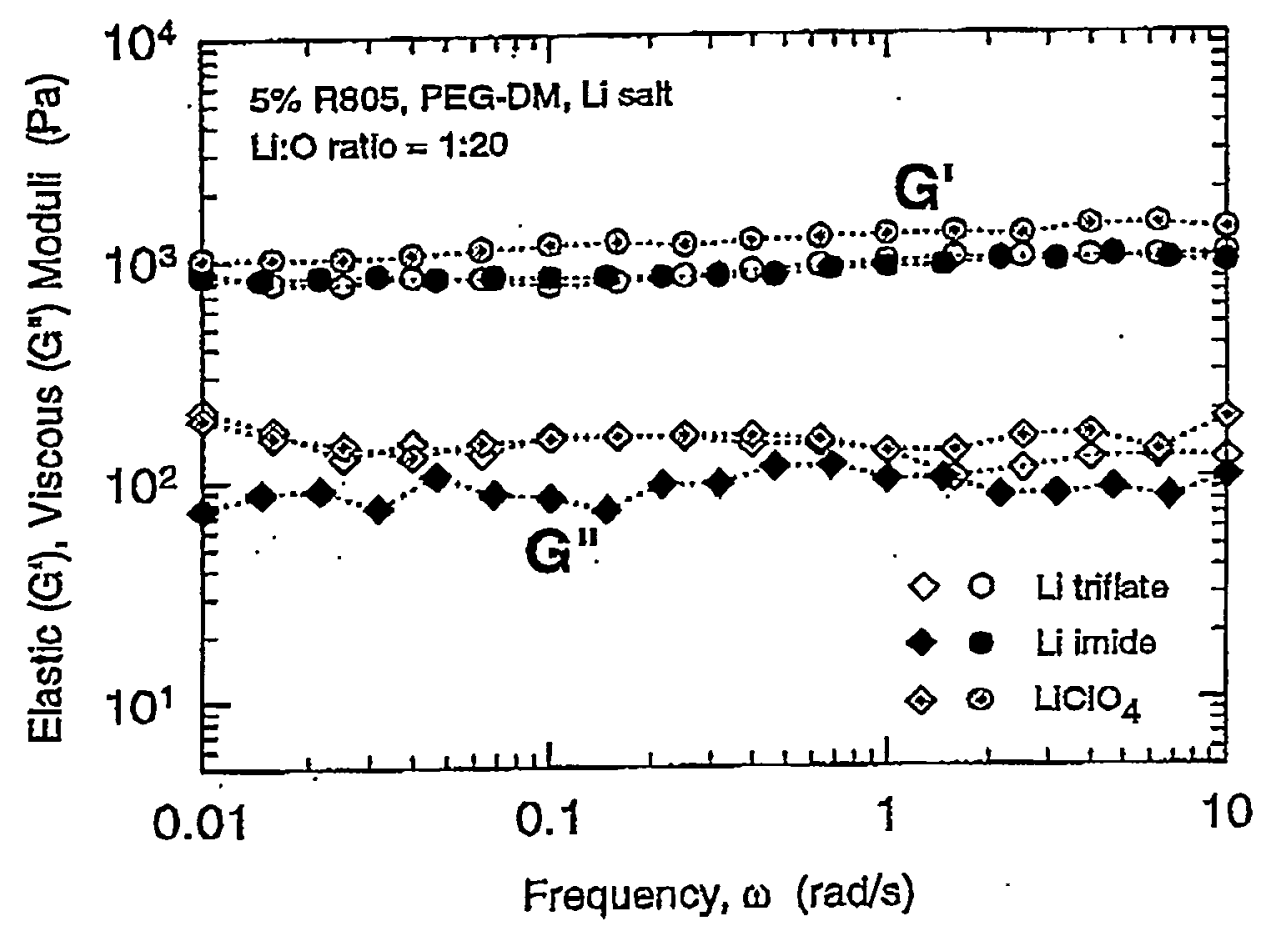

Figure to Elastlc $\left(G^{\prime}\right)$ and Viscous $\left(G^{n}\right)$ moduli versus frequency for composite electrolytes containing $5 \%$ R805 fumed sllica in PEG-DM/ Lithium salt solutions. Data is shown for three different lithium salts.

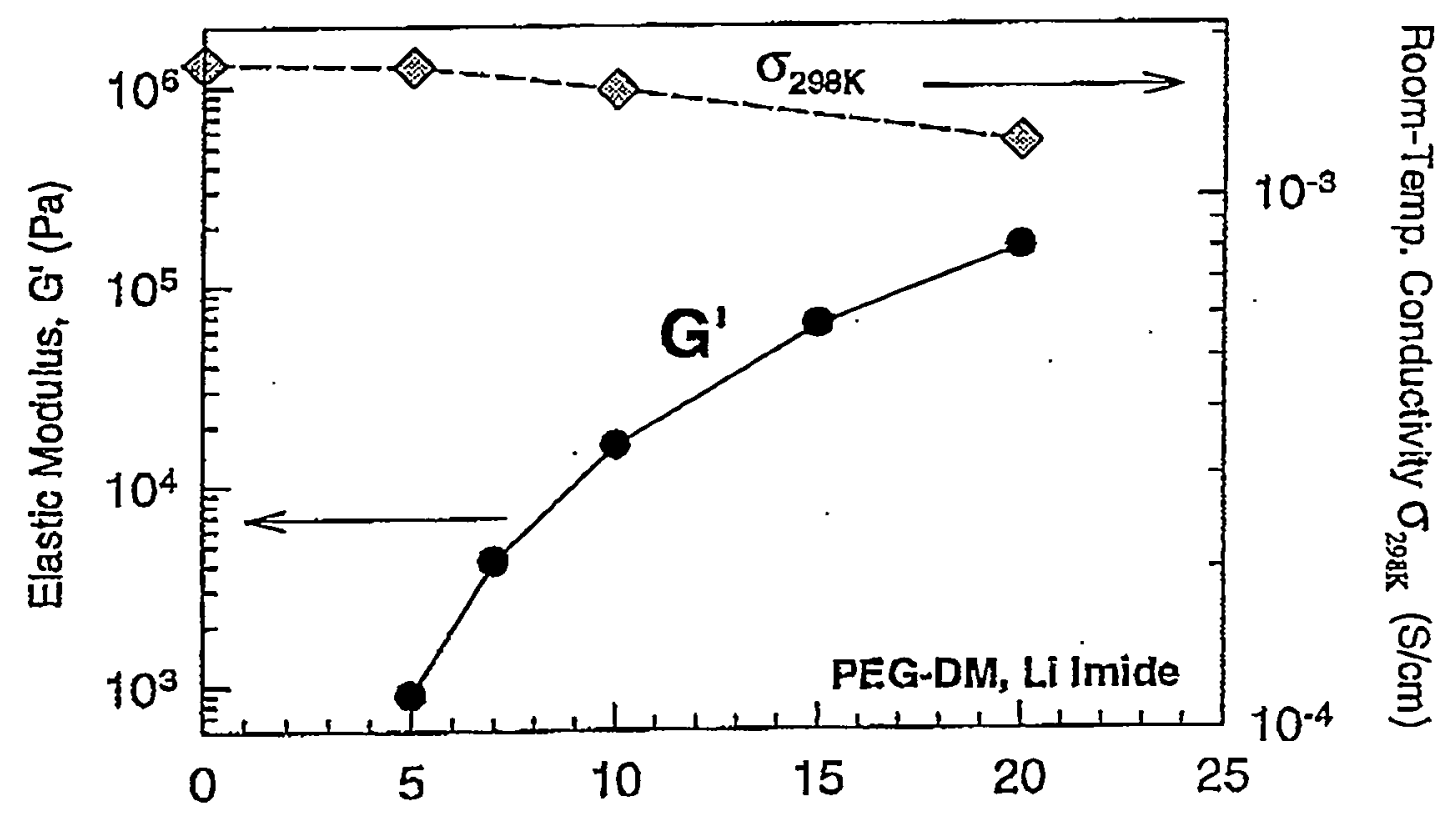

Fumed Silica (A805) weight \%

Figure 11 Variation of elastic modulus $\left(G^{\prime}\right)$ and room-temperature conductivity $\left(\sigma_{298 k}\right)$ with silica (R805) weight fraction for the composite electrolytes under study. ... . 
conductivity. The conductivity of the $20 \%$ fumed-silica composite is only $15 \%$ less than that of the pure PEG-DM/Li imide solution and still exceeds $10^{-3} \mathrm{~S} / \mathrm{cm}$. The drop in conductivity is much smaller than would be expected from simple volume-filling effects, and results from the open, branched nature of the fumed silica network that does not hinder motion of the $\mathrm{Li}^{+}$ions.

The composite polymer electrolytes are also shear sensitive and show significant drop in viscosity with shear stress or shear rate. This is illustrated in Figure 12 where we find a four order of magnitude decrease in viscosity with shear rate. Silica networks are comprised of physical bonds that are susceptible to shear, and this shear-thinning can be used advantageously to process these materials to desired configurations. On cessation of shear, the network structure reforms almost instantaneously and reverts to its initial state [30]. Further mechanical strength and dimensional stability is available through cross-linking.. The response of cross-linking a fumed silica/PEG-DM composite is shown in Figure 13. Using the method developed in Baker's group, a fumed silica containing both octyl and methacrylate surface groups was studied. Prior to cross-linking, the sample is a physical gel as evidenced by $G^{\prime}>G^{\prime \prime}$ and both moduli being relatively frequency independent. Following cross-linking, the elastic modulus increases by almost two orders of magnitude to yield a mechanically robust composite electrolyte. Note that the room temperature conductivity for this system still exceeds $1 \times 10^{-3} \mathrm{~S} / \mathrm{cm}$ (Figure 9).

\section{Summary}

We are at the threshold of developing a new class of highly processable polymer electrolytes that offer a broad spectrum of favorable mechanical properties and desirable electrochemistry. The beauty of these electrolytes lies in their ability to be readily processed yet become self-supporting gels instantaneously following processing. Further mechanical strength and dimensional stability, if desired, can be easily imparted by cross-linking the fumed silica, and the desired mechanical properties can be tuned independently of the electrochemistry. We now plan to build on these initial successes by defining the scope and utility of our route to composite electrolytes. The critical issues that remain to be resolved form the crux of the proposed work.

\section{Patents Publication \& Presentations}

S.A. Khan, P.S. Fedkiw, G.L. Baker, J. Fan, S.R. Raghavan, A Composite Polymer Electrolyte Based on Surface-modified Fumed Silica Fillers, Patent disclosure filed. Currently being worked for filing patent.

S. R Raghavan, M.W. Riley, P.S. Fedkiw and S.A. Khan, Composite Polymer ElectrolytesBbased on Polyethylene Glycol and Hydrophobic Fumed Silica: Dymamic Rheology and Microstructure, Macromolecules, submitted 1997.

J. Hou and G.L. Baker, Preparation and Characterization of Cross-linked Composite Polymer Electrolytes, Chem. Mater. (in preparation, will be submitted as soon as patent is filed).

S.R Raghavan and S.A. Khan, Shear-thickening Response of Fumed Stlica Suspensions Under Steady and Oscillatory Shear, J. Coll. Int. Sci., 185(1) (1997) 57.

J. Fan and P.S. Fedkiw, Composife Polymer Electrolytes Prepared From Fumed Silica, PEO Oligomers and Lithium Salts for Applicatton in Lithium Batteries, J. Electrochem. Society, 144 (1997), 399.

J. Fan, S.R. Raghavan, P.S. Fedkiw, S.A. Khan, J. Hou, and G.L. Baker, Composite Polymer Electrolytes Based on Surface-Modified Fumed Silica for Application in Rechargeable Lithitum Batreries, Proc. 192 Meeting of the Electrochemical Society (1997). 


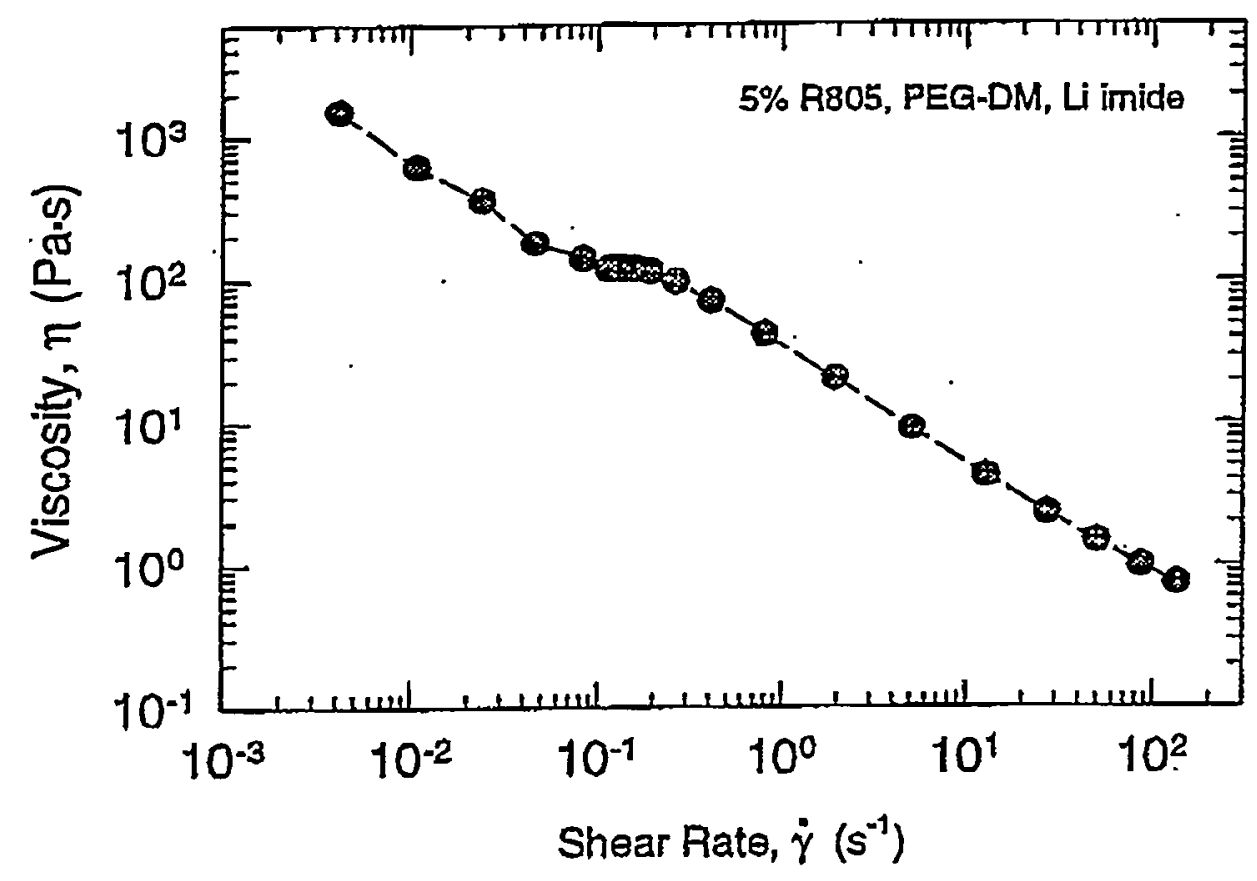

Figure 12 Steady-shear viscosity as a function of shear-rate for a composite polymer electrolyte containing 5\% R805 fumed sillca in a PEG-DM - lithlum imide solution.

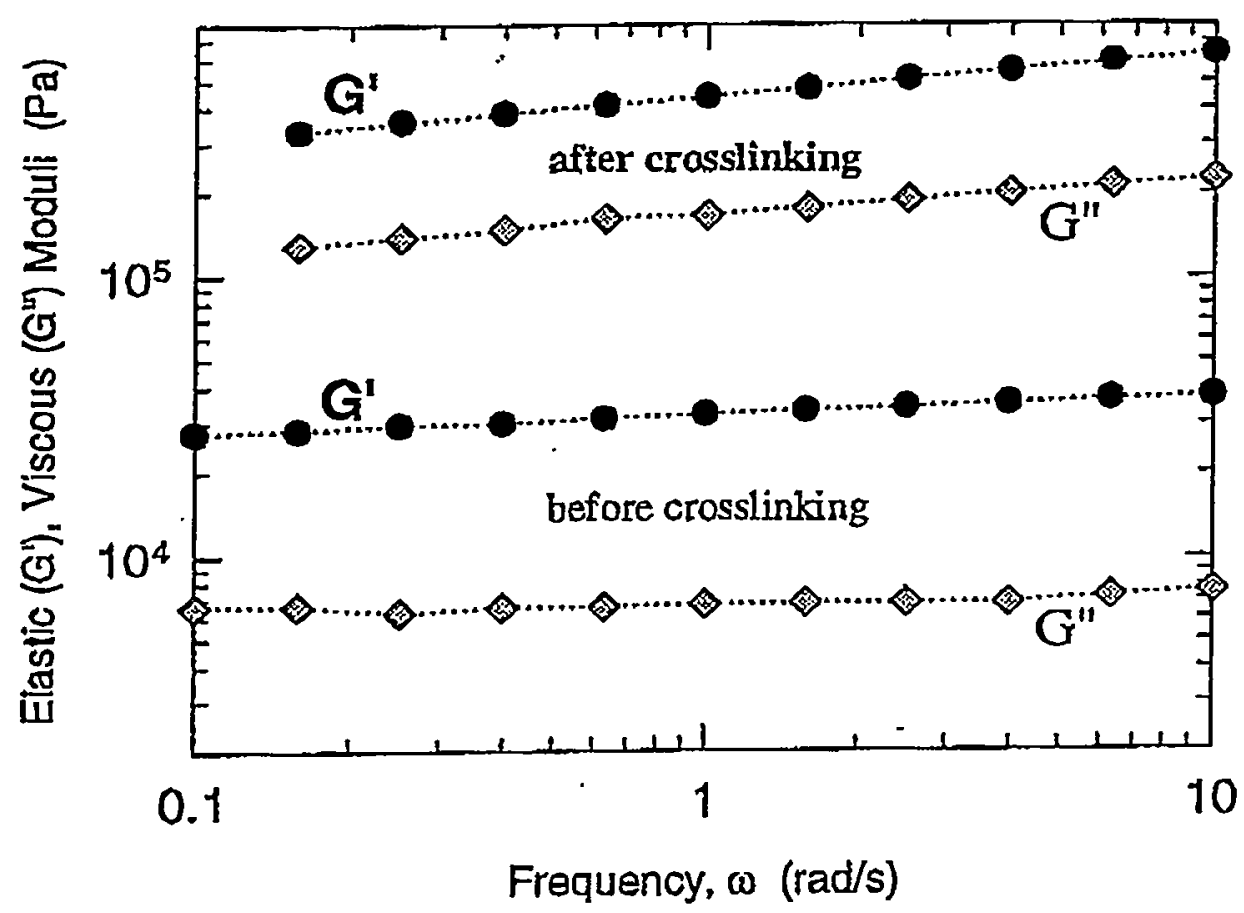

Figure 13 Dynamic moduli ( $G$ ' and $G^{\prime \prime}$ ) before and after crossilinking for composites containing $10 \%$ to 2 (methacrylate-functionalized) fumed silica and 10\% butyl methacrylate in a PEG-DM/ $\mathrm{LiClO}_{4}$ matrix. 
P.S. Fedkiw, Composite Electrolytes for Lithium Batteries, Invited Presentation, University of Washington, Department of Chemical Engineering, May 19, 1997.

S. R Raghavan, S.A. Khan, Shear-induced Microstructure of Flocculated Suspensions of Fumed Silica J. Rheolagy 39(6) (1995) 1311.

S.R. Raghavan, S.A. Khan, Composite Polymer Electrolytes Based on Fumed Silica: Mechanical Response and Processability, Proc. 190th Meeting of the Electrochemical Society (1996).

J. Fan, P.S. Fedkiw, Composite Polymer Electrolytes Prepared From Fumed Silica, PEO Oligomers and - Lithium Salts for Use in Rechargeable Lithium Batteries, Proc. 190th Meeting of the Electrochemical Society (1996).

S.A. Khan, Rheology \& Microstructure of Fumed Silica Suspensions and Gels: Applications in Emerging Technologies, Invited Presentation, University of South Carolina, Department of Chemical Engineering, Columbia, SC, November 301995.

S.A. Khan, Rheological Behavior of Fumed Stlica Suspensions, Invited Presentation, Fine Particle Society Mtg., Chicago, IL, August 1995.

S.R. Raghavan, S.A. Khan, Strain-thickening and Shear thickening in Suspensions: Correlation between Steady and Dynamic Properties, Ann. Mtg. AIChE, Chicago, Hlinois, Nov. 1996.

S.R. Raghavan, S.A. Khan, Shear-thickening Behovior of Fumed Silica Suspensions, 67th Ann. Mtg. Soc. Rheol., Sacramento, California, Oct. 1995.

J. Qiao and Gregory L. Baker. Unsaturated Ethylene Oxide-Segmented Polymers via ADMET Polymerization Chicago, 190 $0^{\text {th }}$ Meeting of the Electrochemical Society, October 61996. 